\title{
AS RELAÇÕES JOCOSAS FUTEBOLÍSTICAS. FUTEBOL, SOCIABILIDADE E CONFLITO NO BRASIL
}

Édison Gastaldo

\section{Introdução}

O objetivo deste artigo é o de explorar elementos de um fenômeno social particularmente intenso no Brasil, que denomino "relações jocosas futebolísticas" (Gastaldo 2005a). Trata-se de formas lúdicas de interação social mediadas pelo futebol, na forma de provocações, sátiras, pilhérias, desafios ou apostas, isto é, "jogos" paralelos aos jogos de futebol propriamente ditos. Em geral, tais relações ocorrem entre participantes afetivamente vinculados a equipes adversárias, e a jocosidade é manifesta em situações públicas. A pesquisa foi realizada a partir de trabalho de campo etnográfico em bares da cidade do Rio de Janeiro onde são transmitidas partidas de futebol pela televisão. Este artigo é uma produção relativa à pesquisa "Futebol, sociabilidade e conflito no Brasil", financiada pelo CNPq com bolsa de pósdoutorado sênior (PDS), e executada no Museu Nacional, sob a supervisão do Prof. Dr. Gilberto Velho.

\section{As relações jocosas na teoria antropológica}

A noção de "relações jocosas" é bastante conhecida na antropologia, em particular pelo célebre artigo "Parentés à plaisanteries", de Marcel Mauss (1926), publicado no Brasil em 1979, no volume a ele dedicado na coleção "Grandes Cientistas Sociais", sob o título "As relações jocosas de parentesco". Embora este belo texto não seja o primeiro registro desta noção, ele foi certamente importante em sua popularização e de certa forma responsável pelo condicionamento da leitura que dele se fez. A forte ênfase de Mauss nos aspectos ligados ao parentesco ao tratar das relações jocosas e seu uso de ilustrações exclusivamente oriundas de sociedades tribais acabaram 
reduzindo o uso desta noção a um subtema dos estudos de parentesco em etnologia. Radcliffe-Brown percorreu o mesmo caminho: considerar as relações jocosas como fenômeno subordinado à questão do parentesco. ${ }^{1}$ Para ele, tais relações cumprem a função de "estabelecer e manter equilíbrio social num tipo de situação estrutural que resulta, em muitas sociedades, do casamento" (Radcliffe-Brown 1973:137) Entretanto, a denominação inglesa do conceito (joking relationships) ainda permite certa abertura para a compreensão de relações entre parceiros não necessariamente aparentados, o que o próprio Brown reconhece ao incluir relações jocosas tanto entre grupos de indivíduos não aparentados quanto entre membros de tribos ou clãs distintos. Já no termo francês (parentés à plaisanteries, literalmente "parentesco de brincadeira"), ${ }^{2}$ o fenômeno fica restrito a um aspecto do tema geral das relações de parentesco.

Talvez a posição mais aproximada do fenômeno - que busco circunscrever neste artigo - esteja em sua primeira definição, proposta em 1920 por Robert H. Lowie em seu clássico Primitive society. ${ }^{3}$ Lowie referiu-se ao fenômeno da relação jocosa por vários termos (joking alliances, joking partnership e joking relationship, por exemplo), embora o primeiro deles tenha sido privileged familiarity ("familiaridade privilegiada"), que dá título a um dos capítulos de seu livro (Lowie 1920:99-ss). Para este autor, a ênfase na compreensão do fenômeno está antes na relação propriamente dita (hoje diríamos "interação social") do que nos liames estruturantes do parentesco. Em todos os seus termos, Lowie enfatiza a relação entre indivíduos ou grupos com outros indivíduos e grupos, e o modo como a jocosidade medeia esta interação, negociando com humor situações sociais de conflito. Os laços de parentesco aparecem como parte do quadro estruturante geral daquelas sociedades ${ }_{1}^{4}$ mas não como o "motivo" daquela modalidade de relação.

Embora em um quadro teórico distante do que viria a ser o funcionalismo britânico (discípulo de Franz Boas e um dos primeiros expoentes do chamado "culturalismo norte-americano"), Robert Lowie percebeu nas relações jocosas uma "função moral" bastante importante, a de controle social dos valores do grupo, cuja transgressão corresponderia o risco da ridicularização do transgressor por seu parceiro de jocosidade:

A relação [jocosa] tem uma função mais séria. Os gozadores de um homem são também seus censores morais. Se ele de alguma maneira transgrediu o código tribal de ética e etiqueta, um gozador pode repentinamente confrontá-lo em uma ocasião pública e zombar dele por sua falta em voz alta, para que se sinta cumulado de vergonha. Ainda assim, ele não tem como se recompor, a não ser aguardando a oportunidade da desforra (Lowie 1920:100). ${ }^{5}$ 
O ponto enfatizado por Lowie é fundamental para a compreensão das relações jocosas futebolísticas: à primeira vista, trata-se apenas de futebol, mas o sistema de valores que fundamenta as interações é basicamente o enquadramento moral da sociedade como um todo, com sua demanda pela defesa da honra, da dignidade e da autonomia, atributos bastante vinculados à identidade de gênero masculino no Brasil.

Em 1952, no seu clássico Structure and function in primitive society, ${ }^{6}$ Radcliffe-Brown apresenta uma definição de "relações jocosas" que vale a pena transcrever:

O termo "relação jocosa" significa uma relação entre duas pessoas na qual uma delas tem permissão, pelos costumes, e em alguns casos a obrigação, de zombar ou fazer graça de outra que, por seu turno, não pode se ofender. É importante distinguir duas variedades principais. Em uma delas, a relação é simétrica; cada uma das pessoas provoca ou faz gozação da outra. Na outra variedade, a relação é assimétrica; A faz graça à custa de B e B aceita a provocação com bom humor, mas sem retaliação; ou A provoca B tanto quanto queira e B, em troca, provoca A apenas um pouquinho (Radcliffe-Brown 1952:90). ${ }^{7}$

No caso específico das relações jocosas futebolísticas, o que ocorre é uma modalidade híbrida entre as duas variedades apresentadas por Brown. Na medida em que a motivação da jocosidade é o desempenho de cada equipe de futebol defendida pelos parceiros e que o resultado dos jogos é imponderável, a cada rodada dos diferentes campeonatos as relações de força entre as equipes se alteram, resultando em uma variedade que poderia ser chamada, nos termos propostos por Brown, "assimétrica alternada", embora a "alternância" esteja condicionada aos fatos do jogo. Por vezes, uma determinada equipe está em "boa fase" ou "má fase", colecionando sucessos ou fracassos, por mais ou menos tempo. ${ }^{8}$ No entanto, se considerarmos que a lealdade demandada dos torcedores é vitalícia, há amplo espaço para ascensões e quedas ao longo da vida de um torcedor e seus parceiros de gozação.

\section{Futebol, sociabilidade e conflito no Brasil}

Já há muitos anos, Simoni Guedes (1977) definiu o futebol brasileiro como "instituição zero", isto é, um significante vazio, mas pleno de potencialidades de significação. Em outras palavras, no Brasil, o campo simbólico do futebol pode ser tomado como exemplo de muitas coisas diferentes: da tradicional metonímia da Seleção brasileira como "o povo brasileiro em campo" às 
mazelas dos dirigentes de clubes como metáfora da classe política e suas negociatas, passando pelo desempenho de cada jogador em campo - ou mesmo fora dele - metáfora de condutas privadas, honrosas ou desonrosas. Vários autores já apontaram a forte presença de elementos do universo simbólico futebolístico na cultura brasileira contemporânea; portanto, não vale a pena nos determos demasiado neste ponto. ${ }^{9}$ Para os fins deste artigo, interessa destacar o uso de situações relacionadas ao futebol como mote de relações jocosas e, em particular, o modo como tais relações evidenciam valores morais bastante caros à sociedade brasileira.

Apesar das controversas relações das organizações que regulam a prática futebolística (federações, clubes, tribunais de justiça desportiva etc.) com as esferas da política, da mídia e da economia, há um amplo espaço de apropriação destes fatos sociais pelos membros da sociedade na vida cotidiana. Por exemplo, a absoluta maioria dos torcedores nada possui de "seu clube" - carteirinha de sócio, camiseta "oficial", cadeira cativa etc. que não seja o vínculo afetivo voluntário. O "pertencimento clubístico" é, no Brasil, uma escolha importante, frequentemente mediada na infância por relações familiares e que inscreve o torcedor em um complexo sistema de classificações, que estabelece aliados e adversários instantaneamente, articulando lógicas identitárias em âmbito local, regional, nacional e internacional. ${ }^{10}$ Os fatos do jogo operam como índices indiscutíveis de superioridade momentânea entre pares relacionais de jocosidade. A cada rodada de um campeonato - e sempre há um campeonato ou torneio em andamento as relações de força entre as equipes se alteram, motivando um circuito de sociabilidade cotidiana, marcada por um forte viés de gênero. Embora nos últimos anos tenha havido um expressivo crescimento da participação feminina no universo futebolístico (que se manifesta não só na audiência, mas também dentro de campo, vide o sucesso internacional conquistado pela Seleção brasileira de futebol feminino), este universo continua a ser simbólica e hegemonicamente um território masculino.

Assim, as relações jocosas futebolísticas conectam-se intimamente ao que se denominou "homossociabilidade", forma lúdica de interação entre participantes de um mesmo sexo, no caso, homens. A sociabilidade entre homens pode por vezes derivar para formas bastante agressivas de interação que trafegam no estreito limite do que possa ser efetivamente chamado de "brincadeira". Tais relações ocorrem em uma base de reciprocidade — quem "sacaneia", "goza", "toca flauta" ou "corneta", hoje, aceita de modo tácito a possibilidade de ser a vítima de amanhã... - que, articulada ao sem-fim de campeonatos e torneios, estabelece um fluxo cotidiano de motivos para interação jocosa entre pares relacionais. 
As performances masculinas ocorrentes nos ambientes pesquisados são uma manifestação interacional cotidiana de aspectos profundos da cultura masculina no Brasil, evidenciando lógicas simbólicas de pertencimento e exclusão que, mediadas pelo futebol, resolvem pela jocosidade tensões que em casos extremos podem conduzir a confrontos físicos e violência. É evidente que brigas e conflitos entre torcedores ocorrem, embora sejam antes exceção do que regra. ${ }^{11}$ Há que se considerar aqui o papel da imprensa, sobrevalorizando o "espetáculo midiático" de uma guerra de torcidas, muito mais noticiável do que a gozação cotidiana sem consequências, "levada na esportiva", em elevadores, bares, portarias e escritórios, mais frequente, mas menos espetacular. O universo do futebol profissional, desta forma, fornece em nossa sociedade, local e oportunidade para pôr em ação formas competitivas de sociabilidade. A seguir, apresento alguns dados etnográficos que ilustram elementos dessa "gramática da jocosidade futebolística" a partir do relato de uma situação de campo tomada como exemplo. Outras situações derivadas do mesmo trabalho de campo serão oportunamente expostas para melhor ilustrar os tópicos que se quer ressaltar.

\section{Uma experiência de campo}

A narrativa da situação a ser analisada foi elaborada a partir de minhas anotações em diário de campo durante investigação etnográfica em bares e locais públicos do Rio de Janeiro onde são exibidas partidas de futebol pela televisão. A situação em questão ocorreu em 13 de maio de 2009, pouco depois do meio-dia, no anexo de um restaurante dentro de uma universidade, onde há um pequeno café, com balcão e mesas. Naquela noite, seria disputada a primeira partida das quartas-de-final da Copa do Brasil 2009, entre Flamengo e Internacional de Porto Alegre. Ambos os times tinham sido campeões em seus estados, e tudo indicava um confronto equilibrado, embora naquele momento o Internacional fosse apontado como favorito pela imprensa. Eu havia pedido um café e aguardava de pé, junto ao balcão. Na outra ponta do mesmo, havia um professor da universidade, muito à vontade no local e falando bastante alto, para todos os presentes escutarem. Transcrevo a seguir o trecho de meu diário de campo em que o episódio é narrado em detalhes:

Tendo notado um detalhe rubro-negro na roupa do rapaz que servia os cafés, o professor pergunta a ele: "Você é Flamengo?" Ante a afirmativa do rapaz, ele provoca: "O que eu quero saber é se você vai chorar muito ou se vai chorar pouco esta noite!" O rapaz reage, num muxoxo: "Que que é isso? Vai ser 3 a 1 pro 
Mengão." A moça que atende no balcão intervém em favor do colega, dizendo que o professor "não tem amor a um time" e, por isso, não poderia ficar zombando do time dos outros. O professor se finge de indignado e proclama seu pertencimento: "Eu sou do América e por isso posso gozar de quem eu quiser! Tudo que quiserem falar mal do América podem falar, porque é tudo verdade!" Percebo que enquanto o professor fala, me olha de soslaio, percebendo minha atenção. Para ver o que acontece, resolvo participar do "jogo", lançando uma provocação ao rapaz: "Pra fazer 3 a 1, o Flamengo tem que fazer os gols e não pode errar pênalti!", referindo-me à fase então vivida pelo time carioca. Sem um bom centroavante, gols incríveis eram perdidos a cada jogo; até mesmo um pênalti fora desperdiçado contra o Cruzeiro de Minas Gerais dias antes. O rapaz replica: "Os gols que a gente não fez no Cruzeiro está guardando pro jogo de hoje." A meu turno, ironizo: "Ah, então é uma questão de economia, entendi..." O professor comenta em voz alta com a moça, olhando para mim: "Esse gaúcho deve ser gremista..." Digo: "Não, sou colorado mesmo." "Colorado? Ihhhhh..." A tensão previamente construída na situação torna novas provocações desaconselháveis. Em seguida, o professor me pergunta se eu estava no Rio para assistir ao jogo. Com minha resposta negativa, a situação "esfria", enquanto os cafés são servidos e cada um vai para sua mesa. Na saída, me despeço dos presentes e saio. Ao passar pela porta, o professor me provoca com um desafio: "Volta aí amanhã! Não pode só tirar sarro e ir embora. Amanhã tem que voltar!" Concordo com ele e me despeço. Naquela noite, o jogo foi difícil e disputado, mas terminou 0 a 0 . Eu estava decidido a voltar lá no dia seguinte caso o Internacional perdesse, para honrar a palavra empenhada na situação. Se o Inter ganhasse, eu havia decidido não comparecer, para não deixar a impressão de estar ali só para tripudiar do jovem funcionário. Como o jogo empatou sem gols e a decisão ficou postergada para a semana seguinte, em Porto Alegre, senti-me desobrigado a voltar. Não haveria nada a dizer sobre o jogo, a não ser que colocasse mais desafios, desta vez em relação ao jogo da semana seguinte. Preferi não interferir mais.

A partir dessa situação, podem ser identificados alguns elementos constituintes de uma "gramática interacional" das relações jocosas futebolísticas. Gostaria de destacar três regras tácitas desta gramática: a qualificação dos participantes, o conhecimento de fundo e a dinâmica do desafio.

\section{a) Qualificação dos participantes}

Prévia a qualquer estabelecimento de uma situação de interação jocosa futebolística é a qualificação de seus participantes como "torcedores" de um 
ou outro time. Este elemento de definição da situação relaciona instantaneamente os participantes - aliados ou adversários, momentâneos ou perenes. Em boa parte do Brasil, o "clubismo" ou "pertencimento clubístico" implica o imediato reconhecimento de um grande rival em nível local. ${ }^{12}$ Como já destaquei em outro artigo (Gastaldo 2005a), esta rivalidade matiza o sentido atribuído a todos os possíveis jogos em que qualquer dos dois times atue. Desta forma, os torcedores de um time estão sempre envolvidos com quatro equipes, duas fixas e duas variáveis: a) a favor do seu próprio time; b) contra o time rival; c) contra o adversário do seu time; d) a favor do adversário do time rival. Assim, cruzeirenses são automaticamente antiatleticanos; colorados são antigremistas; pontepretanos são antibugrinos etc. E todas as recíprocas são verdadeiras. Na situação apresentada, dois momentos podem ser destacados neste sentido: quando a moça do caixa toma o partido do funcionário, desqualificando o professor como participante da interação jocosa por não "ter amor a um time", este alega seu pertencimento clubístico a uma equipe improvável, o América/RJ. Visto como uma das piores equipes do Rio de Janeiro, o América ocupa um lugar muito especial no futebol brasileiro. ${ }^{13}$ Tendo obtido destaque entre os anos 40/60, equipe tradicional do bairro carioca da Tijuca, o América há muitos anos não ganha títulos de nenhum nível ${ }_{1}^{14}$ estando atualmente na terceira divisão do futebol brasileiro. A maioria absoluta dos torcedores cariocas vincula-se a um dos chamados "quatro grandes": Botafogo, Flamengo, Fluminense e Vasco da Gama. A situação do "Ameriquinha" é de tamanha decadência que desperta simpatia/compaixão nos outros torcedores: é comum no Rio de Janeiro a afirmação de que o América é o "segundo time de todo carioca". Ou seja, é um time que, como não ameaça ninguém, não sofre rejeição e desperta até mesmo certa simpatia. Ora, incluindo-se nesta posição privilegiadamente inferior, o professor granjeia a possibilidade de zombar de quem quer que seja. Se alguém quiser se vingar zombando do América, o professor concordará, pois "é tudo verdade". Assim, imune a qualquer possível ataque, ele se apresenta na situação como um franco-atirador que não tem nada a perder.

Por vezes, nenhuma palavra precisa ser dita para configurar a qualificação de um participante de uma relação jocosa futebolística. Ao final do Campeonato Carioca de 2010, vencido pelo Botafogo contra o Flamengo após vários anos como vice-campeão, vi um torcedor botafoguense com sua camisa listrada entrar em uma banca de jornal e anunciar a todos os presentes: "Não vou falar nada!" Ficou ali parado, sob as humoradas admoestações do funcionário da banca - que, mesmo sem a camisa do time, evidenciava ser torcedor do Flamengo. Após sua breve performance, o mesmo homem parou ao lado de um vendedor de frutas, também conhecido seu, e fez a 
mesma coisa. Desta vez, a réplica veio mais afiada: "Nossa, que cheiro de naftalina!", disse o feirante, bem-humorado.

O outro momento em que a qualificação dos participantes se mostrou decisiva para os rumos da interação foi quando fiz minha intervenção. Se, poucos momentos antes, a relação jocosa dava-se entre um flamenguista e um americano (vinculado ao jogo somente de modo muito indireto, na condição de "não flamenguista"), a entrada em cena de um adversário direto (um torcedor do Inter) inflamou a situação, levando ao estabelecimento do que Goffman (1998) denomina "prática protetora", na forma de uma pergunta lateral, mas relacionada ao assunto, que de certa maneira aliviou a tensão decorrente da súbita descoberta de oponentes diretos na situação. O "esfriamento" instantâneo da interação foi consequência deste realinhamento.

\section{b) Conhecimento de fundo}

Outra pré-condição para o estabelecimento de uma relação jocosa futebolística é o compartilhamento de informações acerca do contexto futebolístico pelos participantes. Não apenas a situação presente das equipes, mas também os principais jogos e eventos do passado, os nomes e características dos jogadores, sua situação no clube, os eventos ocorridos nos últimos jogos, a posição de cada clube na tabela e assim por diante, são elementos fundamentais nestas práticas de sociabilidade. Como Simmel (1983) assinalava, embora o que defina a sociabilidade como fato social seja a autonomização da forma, esta não prescinde de um conteúdo específico. Aqueles que dão sentido às relações jocosas futebolísticas provêm, por sua vez, do conhecimento de fundo compartilhado acerca do contexto esportivo. Assim, a participação em situações de relação jocosa futebolística depende, em boa parte, da constante atualização dos/as participantes sobre os fatos do futebol, no passado, no presente, e mesmo em relação a previsões - sensatas ou não - sobre o futuro imediato: quem vai ganhar o jogo de hoje? E o campeonato? Como um exemplo do quanto os fatos do jogo e as posições relativas de cada equipe nas competições podem condicionar as interações futebolísticas, podemos pensar na partida final do Campeonato Brasileiro de 2009, em que, pelo arranjo dos pontos na tabela, os torcedores do Internacional precisariam torcer para que o time do Grêmio vencesse o Flamengo, combinação que poderia dar o título de campeão ao Internacional. No final da rodada em que esta situação foi definida, torcedores do Grêmio cantaram nas arquibancadas: "Meeeeeengoooo!", grito de guerra da torcida rubro-negra. Os torcedores do Internacional, por sua vez, cantaram: "Grêêêmioooo!", tradicional grito de guerra do rival. 
Aqui, entra em cena outro fator importante do universo do futebol, a mídia esportiva. Fornecendo não apenas dados sobre o momento presente, mas também "resgates" de grandes momentos do passado, comentários mais ou menos tendenciosos - sobre os eventos em curso e especulações diversas sobre fatores intra e extracampo, o campo discursivo midiático agenda ${ }^{15}$ o campo discursivo futebolístico no cotidiano, evidenciando certos jogadores, destacando certas situações (lances duvidosos, jogadas violentas, atuação da arbitragem, compra e venda de jogadores, lesões e penalidades desportivas etc.) e promovendo o debate em sucessivas edições diárias de jornais impressos e programas de rádio, televisão e internet. Para tanto, cada periódico jornalístico tem uma editoria fixa dedicada ao esporte, cujo espaço é majoritariamente destinado ao futebol. É evidente que não há aqui uma "manipulação" da opinião pública, uma vez que, como constatamos em observações de campo, os torcedores discordam com frequência das interpretações midiáticas dos fatos do jogo (Gastaldo et alii 2005b). Somente há convergência de interpretações quando o discurso midiático dá razão ao "time do coração", em caso de faltas, impedimentos, pênaltis, expulsões etc. A lógica aqui é a da adesão irrestrita ao próprio clube, em particular diante de torcedores adversários, o que implica o rechaço instantâneo de qualquer afirmação que a contrarie. Ainda assim, a "falação esportiva", esse imenso volume de informações midiáticas disponíveis sobre o futebol, contra a qual Umberto Eco (1984) bradava em vão, permanece como o principal elemento de renovação do repertório para as relações jocosas futebolísticas.

\section{c) Dinâmica do desafio}

Um terceiro elemento fundamental das relações jocosas futebolísticas é a proposição de desafios. Seja na forma de apostas em dinheiro ou mesmo de simples bravatas ou previsões sobre o resultado de um jogo ou campeonato futuro, situações de desafio entre torcedores são bastante frequentes nos locais pesquisados. O desafio é um "jogo dentro do jogo", um envolvimento mais profundo e pessoalizado entre um torcedor e outro, mediado pelos fatos do jogo de futebol. A regra tácita que pode ser identificada a partir das situações analisadas é que há uma espécie de "economia das trocas jocosas": quanto mais um torcedor se apresenta publicamente, agudizando a relação com os demais torcedores tanto mais se expõe a ser zombado pelos outros caso seu prognóstico não se confirme. E, em caso de vitória, sua zombaria pode ser intensificada. Cabe a seus adversários de jocosidade, neste caso, 
conformarem-se com os fatos e esperarem a próxima rodada, quando sempre se pode ir à forra. Como certa vez me disse um informante, com alguma ironia: "Nunca se sabe a rodada de amanhã."

Uma vez feito um desafio, espera-se que ele seja honrado, que as apostas sejam pagas, que as bravatas sejam "engolidas" ou intensificadas. Para tanto, um importante elemento de controle da ordem da interação é o comparecimento ao mesmo local. Em todos os bares que pesquisamos, existe um grupo de frequentadores fiéis que, semana após semana, se encontra para ver os jogos - quaisquer jogos - transmitidos. ${ }^{16}$ Existem, é claro, frequentadores esporádicos, que fazem variar a quantidade de pessoas no bar a cada jogo, mas os habituais detêm certos privilégios, como mesas reservadas e atenção especial dos garçons. Essa característica de pertencimento afetivo a um "pedaço" faz com que uma ruptura na ordem da interação seja evitada. Excessos - como brigas ou agressões verbais mais pesadas - quando ocorrem, trazem consequências já na próxima rodada. Como me disse certa vez um informante a esse respeito: "Tem gente que não sabe brincar. Aí a gente não responde, deixa quieto, melhor não se incomodar..."

Uma modalidade de desafio que merece destaque é a aposta. Apostase dinheiro, é claro, e também caixas de cerveja ou churrascos à custa do perdedor, ou ainda a humilhação de "pagar mico" em praça pública. Certa vez, uma aluna veio me mostrar um pequeno vídeo que havia gravado em seu celular, dizendo ser um material etnográfico para minha pesquisa: tratava-se de uma carroça cheia de torcedores do Grêmio sendo puxada por vários torcedores do Internacional. Ela me disse que no local onde mora há muitos carroceiros e que, sempre que ocorre um Gre-Nal (clássico local entre Grêmio e Internacional), apostam que quem perder tem de dar uma volta na praça sendo "cavalo" dos outros. Como ela era gremista, percebi que o simples fato de me mostrar aquele vídeo após um Gre-Nal perdido pelo Inter era também uma relação jocosa futebolística. Repliquei pedindo a ela outra gravação para incluir na pesquisa, feita desta vez quando o Grêmio perdesse...

Na situação ocorrida no café, a cobrança em relação ao "pagamento" do desafio se deu no final, quando fui interpelado pelo professor para retornar no dia seguinte: sabendo o resultado do jogo, tratava-se de, tendo vencido, poder tripudiar do rapaz do balcão; tendo perdido, ter de suportar suas brincadeiras. Na verdade, nem seria necessário brincar, caso o jogo tivesse tido um vencedor: como já assinalei em outro texto (Gastaldo 2005a), a simples presença no local já é em si performance suficiente para "pagar" ou "cobrar" uma aposta desse tipo. 


\section{Para concluir}

A noção de "relação jocosa" é, na teoria antropológica, um conceito com grande potencial explicativo. Inicialmente concebida por Lowie como um elemento de flexibilidade e descontração em uma ordem social muitas vezes rígida e severa, mas também como elemento de controle social, a relação jocosa atua como uma espécie de "sanção moral" a potenciais desviantes. Marcel Mauss e Radcliffe-Brown, grandes autores que discutiram a noção de "relação jocosa de parentesco" em suas obras, destacaram com maior ênfase seu aspecto de elemento estrutural no sistema de parentesco em sociedades tribais, dedicando relativamente pouca atenção à dimensão "jocosa", lúdica destas complexas formas de interação social. Não obstante, é importante destacar que, além de Lowie, tanto Mauss quanto Brown reconhecem (ainda que de modo incidental) a dispersão destes costumes por várias sociedades, incluindo a ocidental contemporânea, e sua ocorrência também em grupos ou coletividades não necessariamente aparentados.

Nesse aspecto, o universo do futebol na sociedade brasileira tem como parte inextricável de sua apropriação cotidiana - e como boa parte de seu sucesso - a presença de relações jocosas futebolísticas. Neste caso, tais relações trazem em si os elementos centrais do fenômeno destacado na teoria antropológica clássica, mas sob a lógica do jogo de futebol. Neste "jogo dentro do jogo" o grau de envolvimento de um participante é regulado pelo próprio participante: como em um jogo de pôquer, perde-se ou se ganha a quantidade de fichas que se colocou em jogo, em público, na mesa. Honorabilidade, respeito e tolerância, como há setenta anos já afirmava Johan Huizinga (1971), têm uma dimensão lúdica. Saber ganhar e saber perder não são apenas parte do jogo: são parte da vida.

Recebido em 15 de janeiro de 2010

Aprovado em 27 de agosto de 2010

Édison Gastaldo é professor do PPGCS/Unisinos e pós-doutorando do PPGAS/ Museu Nacional/UFRJ. E-mail: <bragastaldo@terra.com.br> 


\section{Notas}

${ }^{1}$ Palmer (1994) ressalta esse mesmo aspecto, acrescentando que, nos dois artigos que publicou sobre o tema, Radcliffe-Brown não apresenta nenhum exemplo de "onde estaria a graça" nas relações jocosas por ele relatadas, concentrando-se somente em assim como Mauss - explorar detalhadamente os laços de parentesco que relacionam os/as participantes e não o conteúdo humorístico das brincadeiras.

2 Na edição em português de "Estrutura e função na sociedade primitiva" (Radcliffe-Brown 1973), joking relationships foi traduzido como "parentesco por brincadeira", o que não corresponde adequadamente à dimensão relacional do fenômeno, uma vez que na expressão original não consta o termo "parentesco" (kinship), mas "relacionamento" (relationship).

${ }^{3}$ Embora Radcliffe-Brown (1949) tenha mencionado sua preocupação com o tema desde 1908, durante sua célebre pesquisa entre os Andamanês, sua primeira formulação teórica sobre as relações jocosas somente ocorreria em meados dos anos 1920, depois de Lowie, portanto.

${ }^{4}$ No caso específico de Lowie, os índios Crow das planícies norte-americanas.

${ }^{5}$ Tradução pessoal. No original: " [...] the [joking] relationship has a more serious function. A man's jokers are also his moral censors. If he has in any way transgressed the tribal code of ethics or etiquette, a joker will suddenly confront him on a public occasion and twit him with it aloud so that he feels like sinking into the ground with shame. Yet he has no redress but to await a chance for requital."

${ }^{6} \mathrm{O}$ artigo foi publicado originalmente no periódico Africa, XIII(3), 1940.

${ }^{7}$ Tradução pessoal. No original: "What is meant by the term 'joking relationship' is a relation between two persons in which one is by custom permitted, and in some instances required, to tease or make fun of the other, who in turn is required to take no offence. It is important to distinguish two main varieties. In one the relation is symmetrical; each of the two persons teases or makes fun of the other. In the other variety the relation is asymmetrical; A jokes at the expense of $\mathrm{B}$ and $\mathrm{B}$ accepts the teasing good humouredly but without retaliating; or A teases B as much as he pleases and B in return teases A only a little."

${ }^{8}$ É célebre no futebol brasileiro o período de 23 anos em que o Corinthians paulista ficou sem conquistar nenhum título. Sua torcida, justamente por esse motivo, ganhou a alcunha de "Fiel".

${ }^{9}$ Roberto DaMatta (1982), Luiz Toledo (1996), Édison Gastaldo (2002), Ronaldo Helal (2001) e Carmen Rial (2003), entre muitos outros. 
${ }^{10}$ Sobre a noção de "pertencimento clubístico" e sua articulação com a dinâmica das rivalidades instantâneas que este implica, ver Damo (1998; 2002).

${ }^{11}$ Em pesquisa etnográfica realizada durante quatro anos em bares onde torcedores assistiam a jogos de futebol, não houve nenhuma ocorrência de confronto físico, embora em quase todos os jogos houvesse discussões acaloradas, no limiar da violência física, mas contidas pela intervenção dos demais participantes.

${ }^{12}$ Embora circunstancialmente possa haver "rivalidades" entre clubes de locais diferentes (como entre Grêmio e Palmeiras nos anos 90, ou Cruzeiro e Internacional nos anos 70), a "alteridade privilegiada" normalmente se dá em relação a outro time da mesma cidade, cujos torcedores coexistem no mesmo espaço urbano.

${ }^{13}$ Para uma perspectiva antropológica sobre a relação entre o América e sua torcida, ver Oliveira 2004.

${ }^{14}$ Os últimos títulos conquistados pelo América foram o Campeonato Carioca de 1960 e o Campeonato dos Campeões, de que participou devido à desistência do Flamengo, em 1982.

${ }^{15}$ Sobre a "teoria do agendamento", relativa ao poder da imprensa de pautar os assuntos que os membros da sociedade discutirão, ver McCombs \& Shaw 1972.

${ }^{16}$ Toledo (2002) relata fato semelhante em São Paulo, onde há bares que são tradicionais pontos de encontro de torcedores do mesmo clube. Estes locais são considerados "território" destas torcidas, e o simples fato de alguém ser identificado ou ali apresentar-se como torcedor da equipe adversária pode ser interpretado como uma provocação que pode ter perigosas consequências.

\section{Referências bibliográficas}

DAMATTA, Roberto. 1982. "Esporte na sociedade: um ensaio sobre o futebol brasileiro". In: (org.), Universo do futebol. Rio de Janeiro: Pinakotheke. pp. 19-42.

DAMO, Arlei S. 1998. Para o que der e vier: o pertencimento clubístico no futebol brasileiro a partir do Grêmio Foot-Ball Porto Alegrense e seus torcedores. Dissertação de mestrado, UFRGS.
. 2002. Futebol e identidades sociais: uma leitura antropológica das rivalidades entre torcedores e clubes. Porto Alegre: Editora da UFRGS.

ECO, Umberto. 1984. "A falação esportiva". In: Viagem na irrealidade cotidiana. Rio de Janeiro: Nova Fronteira. pp. 220-226.

GASTALDO, Édison. 2002. Pátria, chuteiras e propaganda: o brasileiro na 
publicidade da Copa do Mundo. São Paulo/ São Leopoldo: AnnaBlume/ Unisinos. . 2005a. "O complô da torcida: futebol e performances masculinas em bares". Horizontes Antropológicos, 24:107-123. . et alii. 2005b. "Futebol, mídia e sociabilidade: uma experiência etnográfica". Cadernos IHU Ideias, 43:1-26.

GOFFMAN, Erving. 1998. A representação do eu na vida cotidiana. Petrópolis: Vozes.

GUEDES, Simoni L. 1977. O futebol brasileiro: instituição zero. Dissertação de mestrado, UFRJ/Museu Nacional.

HELAL, Ronaldo. 2001. "Mídia, construção da derrota e o mito do herói". In: R. Helal et alii, A invenção do país do futebol. Rio de Janeiro: Mauad. pp. 149-162.

HUIZINGA, Johan. 1971. Homo Ludens: o jogo como elemento da cultura. São Paulo: Perspectiva.

LOWIE, Robert H. 1920. Primitive society. New York: Boni and Liveright.

MAUSS, Marcel. 1983. "As relações jocosas de parentesco". In: R. C. Oliveira (org.), Antropologia. São Paulo: Ática. pp. 164-176.

MCCOMBS, Maxwell; SHAW, Donald. 1972. "The agenda-setting function of mass media". Public Opinion Quarterly, 36:176-187.

OLIVEIRA, Thiago. 2004. "A kombi do diabo: organização e sociabilidade na torcida independente do América F. C.". Trabalho apresentado na XXIV Reunião Brasileira de Antropologia. Mimeo.

PALMER, Jerry. 1994. Taking humour seriously. London: Routledge.

RADCLIFFE-BROWN, Alfred R. 1949. "A further note on joking relationships". Africa: Journal of the International African Institute, 19(2):133-140. 1952. Structure and function in primitive society. London: Cohen and West.
. 1973. Estrutura e função na sociedade primitiva. Petrópolis: Vozes.

RIAL, Carmen. 2003. "Futebol e mídia: a retórica televisiva e suas implicações na identidade nacional, de gênero e religiosa". Antropolítica: Revista Contemporânea de Antropologia e Ciência Política, 14(1):61-80.

SIMMEL, Georg. 1983. "Sociabilidade: um estudo de sociologia pura ou formal". In: E. Moraes Filho (org.), Sociologia. São Paulo: Ática. pp. 165-181.

STEVENS Jr., Phillips. 1978. "Bachama joking categories: towards new perspectives in the study of joking relationships". Journal of Anthropological Research, 34(1):47-71.

TOLEDO, Luiz H. 1996. Torcidas organizadas de futebol. Campinas: Autores Associados/ANPOCS. . 2002. Lógicas no futebol. São Paulo: Hucitec/FAPESP. 


\section{Resumo}

Este artigo apresenta, a partir de dados de pesquisa etnográfica em bares onde se assiste coletivamente a partidas de futebol no Rio de Janeiro, elementos para uma teoria das "relações jocosas futebolísticas". A noção de "relação jocosa" (joking relationship) é bastante conhecida na teoria antropológica pelo clássico artigo de Marcel Mauss (1926), "As relações jocosas de parentesco", embora a origem desta noção esteja em obras anteriores de Robert Lowie e Radcliffe-Brown. No caso deste artigo, trata-se de relacionar o tema da expressão lúdica de sentimentos ao universo simbólico das práticas e consumos futebolísticos no Brasil. A adesão voluntária a um "clube do coração", no Brasil, permite a participação em uma série de "jogos" associados ao futebol, mas paralelos a este, como apostas, desafios e duelos verbais, em que se desenrolam lógicas simbólicas de honra, gênero e poder na sociedade brasileira.

Palavras-chave Futebol, Sociabilidade, Conflito, Relação Jocosa.

\section{Abstract}

This paper presents ethnographic data obtained during the author's fieldwork in sports bars in Rio de Janeiro, Brazil, providing the basis for a theory of 'football joking relationships.' The notion of the 'joking relationship' is well-known to anthropological theory, due in particular to the classic article 'Parentés à plaisanteries' by Marcel Mauss, published in 1926, though its origins can be traced back to earlier works by authors such as Robert Lowie and A. R. Radcliffe-Brown. This paper connects the playful expression of feelings to the symbolic universe of football in Brazilian society. Voluntary support for a favourite club enables the fan to take part in a series of 'games' associated with football, but parallel to it, such as betting, verbal duels and challenges, which involve the symbolic logics of honour, gender and power endemic to Brazilian society.

Key words Football (Soccer), Sociability, Conflict, Joking relationship. 